\title{
Prevalence of vitamin $D$ deficiency and insufficiency in pregnant women: a longitudinal study
}

\author{
V. A. Holmes ${ }^{1}$, M. S. Barnes ${ }^{2}$, H. D. Alexander ${ }^{3}$, P. McFaul ${ }^{4}$ and J. M. W. Wallace \\ ${ }^{1}$ Nursing and Midwifery Research Unit, School of Nursing and Midwifery, Queen's University Belfast BT9 5BN, UK, \\ ${ }^{2}$ Northern Ireland Centre for Food and Health (NICHE), University of Ulster, Coleraine BT52 1SA, UK, ${ }^{3}$ Department of \\ Haematology, Belfast City Hospital, Belfast BT9 7AB, UK and ${ }^{4}$ Royal Jubilee Maternity Hospital, Grosvenor Road, \\ Belfast BT12 6BW, UK
}

Maternal vitamin D insufficiency is associated with childhood rickets and longer-term problems including schizophrenia and type 1 diabetes $^{(1)}$. Whilst maternal vitamin D insufficiency is common in mothers with highly-pigmented skin ${ }^{(2)}$, little is known about the vitamin D status of Caucasian pregnant women.

The aim of the present study was to investigate vitamin D status in Caucasian pregnant women and non-pregnant age-matched controls living at $54^{\circ} \mathrm{N}-55^{\circ} \mathrm{N}$. In a longitudinal study plasma 25 -hydroxyvitamin $\mathrm{D}(25(\mathrm{OH}) \mathrm{D})$ was assessed in ninety-nine pregnant women at 12 , 20 and 35 weeks of gestation and in thirty-eighty non-pregnant women sampled concurrently.

Plasma 25(OH)D concentrations were lower in pregnant women compared with non-pregnant women at 20 and 35 weeks of gestation $(P<0.0001)$. The percentage of pregnant women below the various cut-off values for vitamin D deficiency and insufficiency are presented in the Table.

\begin{tabular}{|c|c|c|c|c|c|c|}
\hline \multirow{2}{*}{$\begin{array}{l}\text { Weeks of gestation. ....... } \\
\text { Plasma } 25(\mathrm{OH}) \mathrm{D} \text { concentrations }(\mathrm{nmol} / \mathrm{l})\end{array}$} & \multicolumn{2}{|c|}{12} & \multicolumn{2}{|c|}{20} & \multicolumn{2}{|c|}{35} \\
\hline & $n^{*}$ & $\% *$ & $n^{*}$ & $\% *$ & $n^{*}$ & $\% *$ \\
\hline$<12.5$ (Severe deficiency) & 2 & 2 & 1 & 1 & 1 & 1 \\
\hline$<25$ (Deficiency) & 35 & 35 & 44 & 44 & 16 & 16 \\
\hline <50 (Insufficiency) & 95 & 96 & 95 & 96 & 74 & 75 \\
\hline$<80$ (Insufficiency) & 98 & 99 & 99 & 100 & 97 & 98 \\
\hline$<100$ (Insufficiency) & 99 & 100 & 99 & 100 & 99 & 100 \\
\hline
\end{tabular}

While severe vitamin D deficiency $(25(\mathrm{OH}) \mathrm{D}<12.5 \mathrm{nmol} / \mathrm{l})$ was not apparent in the non-pregnant controls at any time-point, $>95 \%$ of non-pregnant women were classified as insufficient at each time-point, assuming a cut-off of vitamin D insufficiency of $<80 \mathrm{nmol} / \mathrm{l}$. Vitamin D status was higher in pregnant women who reported taking multivitamin supplements at $12(P<0.0001), 20(P=0.001)$ and 35 $(P=0.001)$ weeks of gestation than in pregnant non-supplement users; however, supplements did not prevent insufficiency $(25(\mathrm{OH}) \mathrm{D}>50 \mathrm{nmol} / \mathrm{l})$.

In summary, there is a high prevalence of both vitamin D deficiency and insufficiency in pregnant Caucasian women considered at low risk of vitamin D deficiency living at $54^{\circ} \mathrm{N}-55^{\circ} \mathrm{N}$. Women reporting multivitamin supplement usage during pregnancy did have higher vitamin D status, but many remained vitamin D insufficient. Suboptimal vitamin D status has important consequences for maternal and neonatal health, and thus, further research is needed to determine the dietary vitamin D intake required to maintain vitamin D sufficiency during pregnancy and to underpin guidelines for supplement use during pregnancy.

1. Holick MF (2004) Am J Clin Nutr 80, 1678S-1688S.

2. van der Meer IM, Karamali NS, Boeke AJ et al. (2006) Am J Clin Nutr 84, 350-353. 